\title{
TRATAMENTO TÓPICO DE ÚLCERA DE ESTASE VENOSA - PROPOSTA PARA PADRONIZAÇÃO
}

\section{THE TOPIC TREATMENT OF VENOUS STASIS ULCER - PROPOSAL FOR STANDARDIZATION}

\author{
Cristiane Stremel Barros Écheli ${ }^{1}$, Cesar Roberto Busato ${ }^{2}$ \\ 1 Autor para contato: Programa Saúde da Família, Castro, PR, Brasil; \\ e-mail: cb-echeli@brturbo.com.br \\ 2 Santa Casa de Misericórdia, Comissão de Controle de Infecção Hospitalar, \\ Ponta Grossa, PR
}

Recebido para a publicação em 24/02/2006

Aceito para a publicação em 03/05/2006

\begin{abstract}
RESUMO
Este trabalho tem por objetivo diagnosticar e padronizar de forma adequada o tratamento tópico da úlcera de estase venosa, em todas as suas fases. Com base na metodologia de coleta de dados em forma de questionário, realizado por enfermeira do Programa Saúde da Família em Castro - Paraná, no mês de maio (2004), ficou constatado que não existe um protocolo para tal e muitas vezes há falta de produtos. Porém, isto não impede que o tratamento seja realizado com eficiência utilizando-se o disponível e adquirindo alguns produtos essenciais.

Palavras-chave: úlcera de estase venosa, curativos, padronização de curativos

ABSTRACT

The objective of this work was to diagnose and to standardize the topic treatment of the venous stasis ulcer, in all its stages, in an appropriate way. The data was collected through questionnaires, submitted by a nurse of the "Programa Saúde da Família” (Family Health Program) in the town of Castro, Paraná, in May 2004. The data evinced that there is no protocol for this procedure and some products are often missing. However, this does not prevent treatment from being efficiently provided through the use of what is available and the acquisition of some essential products.
\end{abstract}

Key words: venous stasis ulcer, bandaging, bandaging standardization 


\section{Introdução}

Úlceras de perna por insuficiência venosa crônica constituem um sério problema de saúde pública, onerando o gasto público e interferindo na qualidade de vida da população (Brasil, 2002).

Como enfermeira do Programa Saúde da Família, na região do $2^{\circ}$ planalto, no estado do Paraná, pude observar pessoas idosas portadoras de insuficiência venosa crônica que desenvolvem modos próprios de se cuidar, com pouca adesão a tratamentos cientificamente comprovados.

Por outro lado, mesmo as orientações que os profissionais fazem aos pacientes em relação ao uso dos produtos, são muitas vezes de eficácia questionável e, portanto, polêmicas. Levando em consideração os poucos recursos que o serviço público dispõe, alguns produtos não justificam seu uso.

Na busca constante da melhoria da assistência, a enfermagem procura observar os pontos falhos e na medida do possível, sanar esses problemas. Para tanto, todos os meios e principalmente a criatividade são exploradas, procurando desenvolvê-la com embasamento científico, em benefício do paciente e para o crescimento da enfermagem como ciência (Lira, 1989).

Na farmacopéia medieval, o óleo de oliva era considerado medicinal para o tratamento de feridas e úlceras. No final do século XIX, Halsted e Carrel descreveram técnicas mostrando a importância da limpeza por meio de desbridamento e a aproximação das bordas através de suturas. Lister, Pauster e Semelweiss demonstraram a importância do controle de infecção, através da assepsia, anti-sepsia das mãos e de instrumentos cirúrgicos (Candido, 2001).

A pele, principal barreira de proteção do organismo tem função de impedir a perda excessiva de líquidos (Bajay, Jorge e Dantas, 2003).

Histologicamente está constituída por epiderme que é a camada mais externa, delgada, avascular e fina da pele; a derme que é a camada mais vascularizada contém fibroblastos, macrófagos, mastócitos e linfócitos, que promovem a cicatrização das úlceras e por fim, o tecido subcutâneo que é constituído de células adiposas separadas do tecido conjuntivo, que atua como isolante térmico e amortecedor contra traumatismos externos (Oliveira, Martinho e Nunes,
2001).

Nos anos 60 e 70 apareceram as primeiras pesquisas sobre o meio ambiente da ferida (Guimarães, 2002).

Na última década ocorreram descobertas importantes sobre a fisiologia da cicatrização, e assim novas terapias tópicas para a cicatrização das úlceras apareceram.

Soluções anti-sépticas com ação bactericida e cito-tóxica, assim como as pomadas enzimáticas associadas a antibióticos demonstram pouca eficiência, interferem no processo cicatricial, e correm o risco de promover resistência bacteriana e hipersensibilidade (Candido, 2001).

A necessidade de padronizar os tratamentos tópicos de úlcera de estase venosa para o Programa Saúde da Família, na cidade de Castro - Paraná levounos a revisão da literatura, ao conhecimento dos medicamentos oferecidos no mercado, bem como sua correta utilização em cada fase da ferida, viabilizando o melhor curativo, respeitando as condições sociais e a realidade de nossa assistência médica.

Ao final deste trabalho foi oferecida aos profissionais do Município uma sugestão de rotina para utilização de produtos para tratamento tópico de úlceras de estase. Padronizar os curativos evitará a utilização de produtos incompatíveis que acarretam desconforto para o paciente, demora na restauração tissular e gastos desnecessários.

\section{Material e método}

Executou-se uma pesquisa quantitativa, com utilização de fontes bibliográficas para embasamento teórico.

O instrumento de coleta de dados foi realizado por meio de um questionário aplicado aos profissionais enfermeiros que trabalham em cinco equipes do Programa Saúde da Família (PSF) no Município de Castro.

Este questionário continha perguntas abertas e fechadas (Anexos) que nos permitiram conhecer, os critérios de avaliação diagnóstica e terapêutica que estes profissionais usavam nos curativos de úlceras de estase venosa. 


\section{Resultados}

Qual o tratamento tópico empregado em úlceras com exsudato?

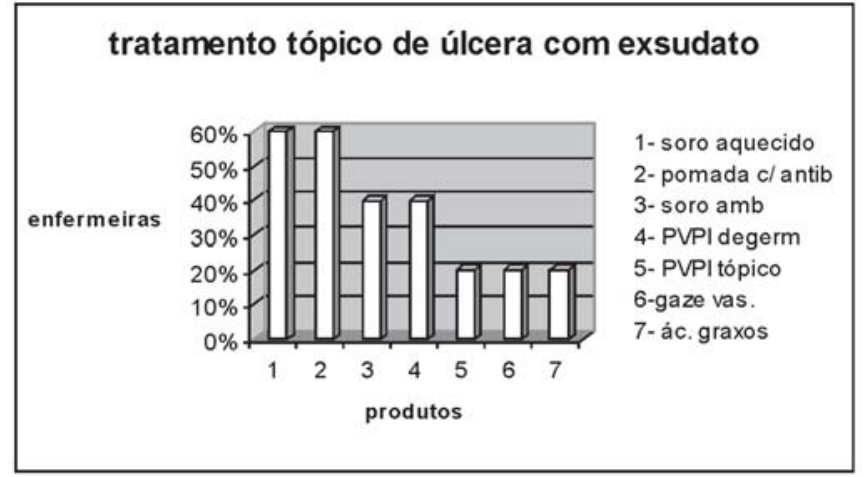

Gráfico 1- Tratamento tópico de úlcera com exsudato.

Sessenta por cento das enfermeiras usam soro aquecido e pomadas com antibióticos para o tratamento de úlceras de estase com exsudato; quarenta por cento, soro a temperatura ambiente e PVPI degermante, enquanto vinte por cento, usam PVPI tópico, gaze vaselinada e ácidos graxos.

Para úlceras com tecido necrosado e crostas, qual o tratamento tópico utilizado?

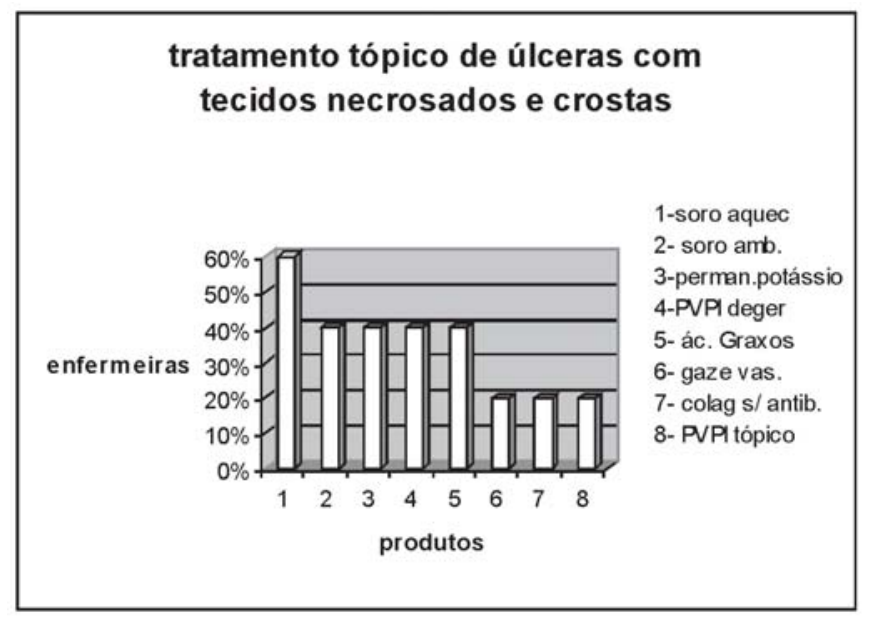

Gráfico 2 - Tratamento de úlceras com tecidos necrosados e crostas.

Sessenta por cento das enfermeiras usam soro aquecido para o tratamento de úlceras de estase com tecido necrosado e crostas; quarenta por cento, soro a temperatura ambiente, permanganato de potássio, PVPI degermante e ácidos graxos, enquanto vinte por cento, usa gaze vaselinada, colagenase sem antibiótico e PVPI tópico.

\section{Qual o tratamento utilizado em úlceras limpas?}

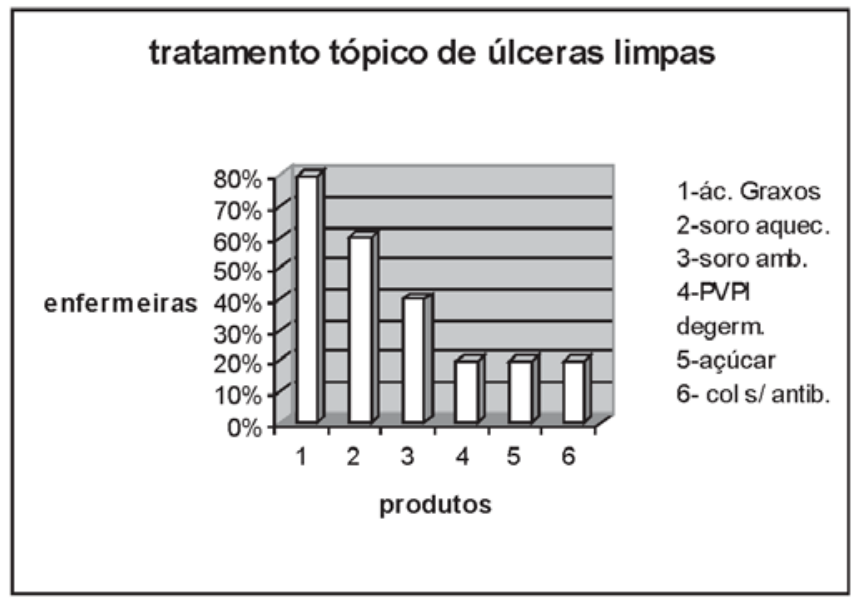

Gráfico 3 - Tratamento de úlceras limpas.

Oitenta por cento das enfermeiras usam ácidos graxos para o tratamento tópico de úlceras de estase limpas; sessenta por cento, soro fisiológico aquecido; quarenta por cento, soro fisiológico à temperatura ambiente, enquanto vinte por cento, PVPI degermante, açúcar e colagenase sem antibiótico.

\section{Nas úlceras com granulação, que tratamento tópico utiliza?}

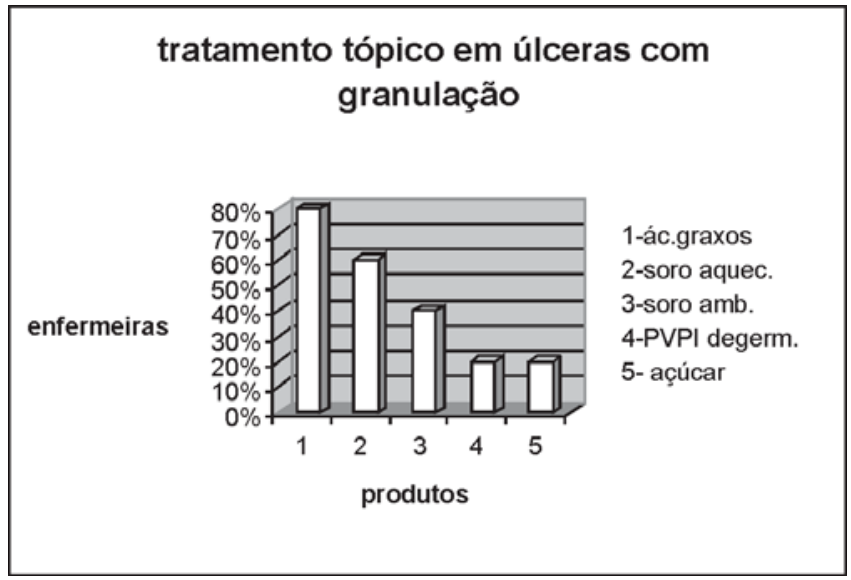

Gráfico 4 - Tratamento de úlceras com granulação. 
Oitenta por cento das enfermeiras usam ácidos graxos para tratamento de úlceras de estase com granulação; sessenta por cento, soro fisiológico aquecido; quarenta por cento, soro fisiológico à temperatura ambiente e vinte por cento PVPI degermante e açúcar.

\section{Discussão}

Ao analisar os dados obtidos, constatou-se, que os profissionais envolvidos não tinham protocolo de atendimento a pacientes com úlcera de estase venosa. Cada enfermeiro age de maneira diferente, utilizandose dos subsídios que o serviço oferece.

Houve poucos relatos sobre aquecimento do soro fisiológico. Para os autores pesquisados em estudo, o que importa é que sejam lavadas as feridas com soro fisiológico a jato. Este, aquecido à temperatura normal da pele, em torno de $36{ }^{\circ} \mathrm{C}$, evita o choque térmico que provoca vaso-constrição dos capilares atrasando a cicatrização.

1- PVP-I degermante, é usado apenas para antisepsia de pele íntegra, como as mãos dos cirurgiões, possuem sabões com tenso-ativos na sua composição apresentando toxicidade no local da aplicação, porém $40 \%$ das enfermeiras usam no tratamento de úlceras com exsudato e com tecido necrosado e crostas, 20\% das enfermeiras ainda usam durante a realizaçÃo do tratamento de úlcera limpa e com granulação.

2- Pomadas com antibiótico (neomicina), receitadas sem critério, podem causar resistência bacteriana, maceração da pele e interferir no processo de cicatrização. Assim, devem ser retiradas da farmácia básica, pois seu uso indiscriminado dificulta a cicatrização. Percebemos neste estudo que $60 \%$ das enfermeiras tratam as úlceras de estase com exsudato com pomadas contendo antibióticos.

3- PVP-I tópico pode ser usado para a antisepsia da pele, embora, seja um produto que pode ser absorvido levando desordens na função da glândula tireóide. Deve ser padronizado apenas para anti-sepsia da pele íntegra.

4- Gaze vaselinada tem função de evitar a aderência do curativo ao leito da ferida, que quando removido pode deteriorar o tecido de granulação já exis- tente.

5- Ácidos graxos essenciais além de cumprirem a função da gaze vaselinada mantêm o leito da ferida úmido enquanto o curativo estiver oclusivo. Quando há muita granulação deve-se ter cautela com seu uso, pois pode levar a hipergranulação dificultando a cicatrização. Está disponível, quando indicado, na Farmácia Básica.

6- Permanganato de potássio pode ser usado como anti-séptico, embora existam estudos que mostraram contaminação por Pseudomonas aeruginosa, é fotossensível e tóxico, porém $40 \%$ das enfermeiras usam no tratamento de úlceras com tecido necrosado e crostas.

7- Colagenase sem antibiótico é indicada para debridamento de áreas necróticas. Estes tecidos devem ser eliminados para evitar maior contaminação da ferida. Comparando o uso do produto colagenase sem antibióticos com antibiótico tópico, verificamos que os usos dos mesmos são inversamente proporcionais, talvez por falta de conhecimento dos profissionais.

8- O uso de açúcar com troca a cada quatro horas para feridas limpas e a cada duas para infectadas, podem funcionar como meio de cultura para bactérias patogênicas. O tratamento com este produto atualmente está restrito a feridas limpas com troca a cada duas horas. A falta de recursos humanos, materiais e tempo inviabilizam os seus uso no Sistema Único de Saúde.

\section{Conclusão}

Há necessidade de se realizar oficinas de capacitação aos profissionais enfermeiros por meio da educação permanente quanto à padronização dos curativos para úlceras crônicas junto às Unidades Básicas de Saúde.

Será através dos aspectos subjetivos vivenciados no contexto de cada um dos sujeitos, entendemse aqui por sujeitos os usuários e os trabalhadores, que a promoção e as ações em saúde serão efetivamente produzidas. Com isto, este vínculo fará que todos os atores envolvidos se responsabilizem pelo tratamento de úlceras crônicas. 
Devemos conhecer o estágio em que a úlcera se encontra e a ação dos medicamentos tópicos, nas diferentes fases do processo de cicatrização. Com estas medidas evitamos gastos desnecessários, perda de tempo e riscos resultantes nos casos de tratamento inadequado.

Espera-se que com a apresentação deste trabalho, as informações nele contidas, possam auxiliar na elaboração de protocolos adequados para o tratamento desta patologia. (Sugestão de protocolo em anexo).

\section{REFERÊNCIAS}

1. BAJAY, H. M.; JORGE, S. A.; DANTAS, S. R. P. E. Curativos e coberturas para tratamento de feridas. In: JORGE, S. A.; DANTAS, S. R. P. E. Abordagem multiprofissional do tratamento de feridas. São Paulo: Atheneu, 2003. p. 81- 89.

2. BRASIL. Ministério da Saúde. Secretaria de Políticas de Saúde. Departamento de Atenção Básica. Manual de Condutas para úlceras neurotróficas e traumáticas. Brasília: Ministério da Saúde, 2002.

3. CANDIDO, L. C. Nova abordagem no tratamento de feridas. São Paulo: Senac São Paulo, 2001.

4. GUIMARÃES, P. C. M. Feridas causadas por doenças vasculares: cicatrização e curativos. In: MAFFEI, F. H. de A. et al. Doenças vasculares periféricas. Rio de Janeiro: Médica científica Ltda, 2002. p. 711-720.

5. LIRA, N. F.; BONFIM, M. E. S. História de enfermagem e legislação. Rio de Janeiro: Cultura Médica, 1989. p. 80.

6. OLIVEIRA, A. C. de.; MARTINHO, G. H.; NUNES, A. A. Feridas e Curativos. In: MARTINS, M. A. et al. Manual de infecção hospitalar - epidemiologia, prevenção e controle. Minas Gerais: Medsi, 2001. p. 325-335. 
ANEXOS

QUESTIONÁRIO PREENCHIDO PELAS ENFERMEIRAS PARA PESQUISA SOBRE O TRATAMENTO TÓPICO DE ÚLCERA DE ESTASE VENOSA.

Marque as terapias tópicas usadas nas úlceras abaixo especificadas.

1- sabonete neutro

2- soro fisiológico aquecido

3-soro fisiológio em temperatura ambiente

4- gaze vaselinada

5- colagenase sem antibiótico (iruxol mono)

6- PVPI tópico

7- PVPI degermante

8- permanganato de potássio

9- água oxigenada

10- pomadas com clostebol (trofodermin)

11-ácidos graxos essenciais (dersani, nyjol, ácido linolêico)

12-açúcar- troca em quantas horas?

13-pomadas com antibióticos (neomicina, nebacetim, iruxol- cloranfenicol)

14-outras drogas não citadas no tratamento tópico. Quais?

ÚLCERAS COM SECREÇÃO PURULENTA

ÚLCERAS COM TECIDO NECROSADO E CROSTAS

ÚLCERAS LIMPAS

ÚLCERAS COM GRANULAÇÃO 
SUGESTÃO DE TRATAMENTO DE ÚLCERAS DE ESTASE PARA ENFERMEIRAS DO PSF DE CASTRO

\begin{tabular}{|c|c|c|c|}
\hline O QUÊ & COMO & COM O QUE & POR QUÊ \\
\hline Úlceras com exsudato & $\begin{array}{l}\text { 1- Limpeza. } \\
\text { 2- Ma nter ferida úmi - } \\
\text { da. } \\
\text { 3- Cobrir a ferida. } \\
\text { 4- Trocar conforme } \\
\text { necessário. }\end{array}$ & $\begin{array}{l}\text { 1- Com soro fisiológi- } \\
\text { co aquecido em jato. } \\
\text { 2- Com produtos áci - } \\
\text { dos graxos essenciais. } \\
\text { 3- Gaze estéril. } \\
\text { 4- Repetir o processo. }\end{array}$ & $\begin{array}{l}\text { 1- Estimula o processo de granu - } \\
\text { lação. } \\
\text { 2- Estimula o processo de granu - } \\
\text { lação. } \\
\text { 3- Evita contaminação bacteriana. } \\
\text { 4- O excesso de exsudato provoca } \\
\text { infecção e retarda a cicatrização. }\end{array}$ \\
\hline $\begin{array}{l}\text { Úlceras com tecido } \\
\text { necrosado }\end{array}$ & $\begin{array}{l}\text { 1- Limpeza. } \\
\text { 2- Realizar debrida - } \\
\text { mento conforme pres - } \\
\text { crição médica. } \\
\text { 3- Manter ferida úmi - } \\
\text { da. } \\
\text { 4- Cobrir a ferida. }\end{array}$ & $\begin{array}{l}\text { 1- Com soro fisiológi- } \\
\text { co aquecido em jato. } \\
\text { 2- Colagenase sem } \\
\text { antibiótico. } \\
\text { 3- Com produtos áci - } \\
\text { dos graxos essenciais. } \\
\text { 4- Gaze estéril. }\end{array}$ & $\begin{array}{l}\text { 1- Estimula o processo de granu - } \\
\text { lação. } \\
\text { 2- Retirar tecidos necrosados. } \\
\text { 3- Estimula o processo de granu - } \\
\text { lação. } \\
\text { 4- Evita contaminação bacteriana. }\end{array}$ \\
\hline Úlceras limpas & $\begin{array}{l}\text { 1- Limpeza. } \\
\text { 2- Manter ferida úmi - } \\
\text { da. } \\
\text { 3- Cobrir a ferida. }\end{array}$ & $\begin{array}{l}\text { 1- Com soro fisiológi- } \\
\text { co aquecido em jato. } \\
\text { 2- Com produtos áci - } \\
\text { dos graxos essenciais. } \\
\text { 3- Gaze estéril. }\end{array}$ & $\begin{array}{l}\text { 1- Estimula o processo de granu - } \\
\text { lação. } \\
\text { 2- Estimula o processo de granu - } \\
\text { lação. } \\
\text { 3- Evita contaminação bacteriana. }\end{array}$ \\
\hline Úlceras com granulação & $\begin{array}{l}\text { 1- Limpeza. } \\
\text { 2- Manter ferida úmi - } \\
\text { da. } \\
\text { 3- Cobrir a ferida. }\end{array}$ & $\begin{array}{l}\text { 1- Com soro fisiológi- } \\
\text { co aquecido em jato. } \\
\text { 2- Com soro fisioló - } \\
\text { gico. } \\
\text { 3- Gaze estéril. }\end{array}$ & $\begin{array}{l}\text { 1- Estimula o processo de granu - } \\
\text { lação. } \\
\text { 2- Mantém o ambiente úmido e } \\
\text { evita a hipergranulação. } \\
\text { 3- Evita contaminação bacteriana. }\end{array}$ \\
\hline
\end{tabular}


SUGESTÃO DE PROTOCOLO DE TRATAMENTO DE ÚLCERAS DE PERNA PARA MÉDICOS DO PSF DE CASTRO

\begin{tabular}{|l|l|}
\hline ETIOLOGIA & ORIENTAÇÃO MÉDICA \\
\hline Venosa & Compressão elástica ou inelástica \\
\hline Arterial & Melhorar o fluxo sanguíneo \\
\hline Neuropática & Evitar traumas \\
\hline
\end{tabular}

\begin{tabular}{|l|l|l|l|}
\hline O QUÊ & COMO & COM O QUE & POR QUÊ \\
\hline $\begin{array}{l}\text { Úlceras com } \\
\text { exsudato }\end{array}$ & $\begin{array}{l}\text { 1- Descobrir o agente } \\
\text { patogênico. } \\
\text { 2- Solicitar exames. }\end{array}$ & $\begin{array}{l}\text { 1- Cultura e antibio - } \\
\text { grama. } \\
\text { 2- Hemograma, glice- } \\
\text { mia. }\end{array}$ & 2- Descobrir doenças associadas. \\
\hline $\begin{array}{l}\text { Úlceras com tecido } \\
\text { necrosado }\end{array}$ & $\begin{array}{l}\text { 1- Debridamento } \\
\text { cirúrgico ou manual. }\end{array}$ & $\begin{array}{l}\text { 1-Cirurgia ou colage - } \\
\text { nase sem antibiótico. }\end{array}$ & 1- Remover o tecido necrosado. \\
\hline Úlceras limpas & $\begin{array}{l}\text { 1- Encaminhar cura - } \\
\text { tivo para enfermeira. } \\
\text { 2- Indicação de com - } \\
\text { pressão. }\end{array}$ & $\begin{array}{l}\text { 1- De acordo com a } \\
\text { rotina já escrita. } \\
\text { ca Elástica ou inelásti- }\end{array}$ & $\begin{array}{l}\text { 1- São profissionais aptas a isto. } \\
\text { 2- Facilita a circulação e conseqüen }\end{array}$ \\
\hline $\begin{array}{l}\text { Úlceras com } \\
\text { granulação }\end{array}$ & $\begin{array}{l}\text { 1- Encaminhar curati - } \\
\text { vo para enfermeira. } \\
\text { 2- Correção vascular } \\
\text { se necessário. }\end{array}$ & $\begin{array}{l}\text { 1- De acordo com a } \\
\text { rotina. } \\
\text { 2- Enxerto. }\end{array}$ & 1- São profissionais aptas a isto. \\
2- Para preencher úlceras grandes.
\end{tabular}

